\title{
Prognostic Factors of Local Control and Survival in Patients Irradiated for Glioblastoma Multiforme (GBM)
}

\author{
JASPAR WITTELER ${ }^{1}$, STEVEN E. SCHILD ${ }^{2}$ and DIRK RADES ${ }^{1}$ \\ ${ }^{1}$ Department of Radiation Oncology, University of Lübeck, Lübeck, Germany; \\ ${ }^{2}$ Department of Radiation Oncology, Mayo Clinic, Scottsdale, AZ, U.S.A.
}

\begin{abstract}
Background/Aim: Standard treatment of glioblastoma multiforme (GBM) includes resection, longer-course radiotherapy and chemotherapy. Some patients cannot tolerate these regimens and may benefit from personalized treatments. This study aims to contribute to treatment personalization by identifying predictors of outcomes after longer-course radiotherapy. Patients and Methods: In 91 patients, number/site/diameter of lesions, Ki-67, MGMT promoter methylation, Karnofsky performance score (KPS), symptoms, gender, age and resection were evaluated for local control and survival. Results: On univariate analyses, gross resection $(p=0.029)$ was significantly associated with improved local control. It maintained significance in the multivariate analysis [hazard ratio $(H R)=1.64, p=0.025]$. MGMT-methylation ( $p=0.004), K P S \geq 80(p=0.022)$ and resection $(p<0.001)$ were significantly associated with improved survival on univariate analyses, unifocal GBM $(p=0.056)$ showed a trend. In the multivariate analyses, MGMT-methylation (HR=3.63, $p=0.009)$, KPS $(H R=2.01, p=0.018)$ and resection $(H R=3.29, p<0.001)$ were significant. Conclusion: Predictors of local control and survival were identified that may guide physicians when tailoring treatments to patients with GBM.
\end{abstract}

Glioblastoma multiforme (GBM) accounts for about 35\% of primary brain tumors in adults $(1,2)$. In the United States, the overall incidence of GBM was reported to be 4.40 per 100,000 inhabitants (3). The prognoses of patients with GBM are generally poor with a 5-year survival probability of only about $5 \%(2,4)$. Better outcomes can be achieved with a tri-modality

This article is freely accessible online.

Correspondence to: Prof. Dirk Rades, MD, Department of Radiation Oncology, University of Lübeck, Lübeck, Ratzeburger Allee 160, 23562 Lübeck, Germany. Tel: +49 45150045401, Fax: +49 45150045404, e-mail: dirk.rades@uksh.de

Key Words: Glioblastoma multiforme, longer-course radiotherapy, local control, survival, prognostic factors. treatment approach that is quite intensive and includes neurosurgical resection followed by longer-course radiotherapy plus concurrent and adjuvant chemotherapy (5-7). However, some patients, particularly if they are elderly or frail, may not be able to tolerate a tri-modality treatment regimen and could benefit from a personalized treatment approach (8). Personalized treatments need to consider the patient's individual situation, personal needs and preferences. Moreover, the patient's survival prognosis and the potential benefit from an intensive treatment program should be considered to avoid over- or undertreatment. Patients with favorable survival prognoses and good chances to benefit from an intensive treatment regimen in terms of improved local control and survival should receive the standard tri-modality treatment $(5,6)$. In contrast, patients with short survival times and little expected benefits from an intensive treatment appear better treated with less aggressive regimens (8). Such regimens may include shorter-course radiotherapy (lasting 3 instead of 6 weeks) with or without systemic treatment and omit extensive neurosurgical resection (8-10).

Tailoring a treatment regimen to a patient's individual situation can be facilitated by applying prognostic factors that allow estimating the probability of local control of the GBM and the patient's remaining survival time. This study aimed to identify predictors of both local control and survival in patients treated with longer-course radiotherapy with or without additional treatment (upfront neurosurgical resection, systemic treatment).

\section{Patients and Methods}

The data of 91 patients irradiated for histologically confirmed GBM between 2005 and 2019 were retrospectively evaluated with respect to local control and survival. The study was approved by the Ethics Committee of the University of Lübeck (15-355A).

The majority of the patients received longer-course radiotherapy with 60.0 Gy in 30 fractions of 2.0 Gy given over 6 weeks $(n=54)$ or $59.4 \mathrm{~Gy}$ in 33 fractions of 1.8 Gy given over 6.5 weeks $(n=19)$. In those 18 patients receiving less than $59.4 \mathrm{~Gy}$, total doses were given as planned in 11 patients (range $=54.0$ to $58.0 \mathrm{~Gy}$ ). In seven patients, the administered dose was less than initially planned; five of these patients received less than $54.0 \mathrm{~Gy}$. Radiotherapy was performed as 3D- 
conformal radiotherapy $(n=53)$ or as volumetric modulated arc therapy $(n=38)$. In all but three patients, radiotherapy was supplemented by systemic treatment with temozolomide. In the entire cohort, 69 patients $(81 \%)$ received upfront neurosurgical resection of the GBM, which was a gross total resection (GTR) in 18 patients $(26 \%)$ and a subtotal resection (STR) in 44 patients (64\%). Extent of resection was not specified in seven patients $(10 \%)$.

A total of 11 characteristics were evaluated for potential associations with local control (defined as freedom from progression or recurrence of the treated GBM lesions and freedom from new GBM lesions) and survival. These characteristics included number of GBM lesions (single vs. multiple), main site of GBM (thalamus $v s$. temporal $v s$. frontal $v s$. parietal $v s$. occipital $v s$. parieto-occipital $v s$. fronto-parietal $v s$. temporo-frontal $v s$. temporo-parietal $v s$. other sites), maximum cumulative diameter of GBM lesions ( $<40 \mathrm{~mm} v \mathrm{~s} . \geq 40$ $\mathrm{mm}$, median=40 mm), Ki-67/molecular immunology Borstel (MIB) 1 labeling index $(<25 \% v s$. $\geq 25 \%$, median $=25 \%)$, O6-methylguanineDNA methyl-transferase (MGMT) promoter methylation (MGMTmethylation) (no vs. yes), Karnofsky performance score ( $\leq 70 v s . \geq 80$, median $=80$ ), number of pre-treatment symptoms ( $1 v s . \geq 2)$, gender (female $v s$. male), age at the start of irradiation ( $\leq 60 v s . \geq 61$ years, median $=61$ years), neurosurgical resection (no $v s$. yes) and extent of resection (GTR vs. STR). Distributions of these characteristics are shown in Table I.

Both local control of GBM and survival were referenced from the first day of radiotherapy. The methods used for the univariate analyses of local control and survival included the Kaplan-Meier method and the log-rank test. $p$-Values of $<0.05$ were considered significant and $p$-values of $<0.06$ were considered indicating a trend. Characteristics achieving significance were additionally evaluated in a multivariate analysis (Cox proportional hazards model). Characteristics that were significant in the multivariate analysis $(p<0.05)$ were considered independent predictors of post-treatment outcomes. Patients were followed until death or for at least 24 months after the start of radiotherapy.

\section{Results}

Median follow-up times were 24 months (range $=1-128$ months) in the entire cohort and 35.5 months (range $=24-128$ months) in patients alive at the last contact.

Data regarding local control were available for 85 patients (93\%). Of these patients, 33 (39\%) experienced a local failure. In the entire cohort, the local control rates at 1 and 2 years were $91 \%$ and $70 \%$, respectively. On univariate analyses (Table II), improved local control was significantly associated with GTR $(p=0.029)$. In the subsequent multivariate analysis, extent of resection remained significant [hazard ratio $(\mathrm{HR})=1.64,95 \%$ confidence interval $(\mathrm{CI})=1.06-2.75, p=0.025]$.

In 53 patients of the entire cohort (58\%), death was recorded during the period of follow-up. Survival rates at 1 and 2 years were $64 \%$ and 53\%, respectively. On univariate analyses (Table III), improved survival was significantly associated with MGMT promoter methylation $(p=0.004)$, a KPS $\geq 80$ $(p=0.022)$ and upfront neurosurgical resection $(p<0.001)$. In addition, a trend was observed for unifocal GBM $(p=0.056)$. In the multivariate analyses, MGMT promoter methylation
Table I. Characteristics that were analyzed with respect to local control and survival.

\begin{tabular}{|c|c|c|}
\hline Factor & $\begin{array}{l}\text { Number of } \\
\text { patients }(\%) \\
\text { for analyses } \\
\text { of local control }\end{array}$ & $\begin{array}{c}\text { Number of } \\
\text { patients }(\%) \\
\text { for analyses } \\
\text { of survival }\end{array}$ \\
\hline \multicolumn{3}{|c|}{ Number of GBM lesions } \\
\hline Single & $72(85)$ & $76(84)$ \\
\hline Multiple & $13(15)$ & $15(16)$ \\
\hline \multicolumn{3}{|l|}{ Main site of GBM } \\
\hline Thalamus & $4(5)$ & $5(6)$ \\
\hline Temporal & $23(27)$ & $25(27)$ \\
\hline Frontal & $19(22)$ & $19(21)$ \\
\hline Parietal & $9(11)$ & $10(11)$ \\
\hline Occipital & $4(5)$ & $4(4)$ \\
\hline Parieto-occipital & $7(8)$ & $7(8)$ \\
\hline Fronto-parietal & $3(4)$ & $4(4)$ \\
\hline Temporo-frontal & $3(4)$ & $3(3)$ \\
\hline Temporo-parietal & $8(9)$ & $9(10)$ \\
\hline Other sites & $5(6)$ & $5(6)$ \\
\hline \multicolumn{3}{|c|}{ Maximum cumulative diameter } \\
\hline$<40 \mathrm{~mm}$ & $35(41)$ & $38(42)$ \\
\hline$\geq 40 \mathrm{~mm}$ & $39(46)$ & $42(46)$ \\
\hline Unknown & $11(13)$ & $11(12)$ \\
\hline \multicolumn{3}{|c|}{ Ki-67/MIB 1 labeling index } \\
\hline$<25 \%$ & $34(40)$ & $37(41)$ \\
\hline$\geq 25 \%$ & $28(33)$ & $31(34)$ \\
\hline Unknown & $23(27)$ & $23(25)$ \\
\hline \multicolumn{3}{|c|}{ MGMT promoter methylation } \\
\hline No & $7(8)$ & $11(12)$ \\
\hline Yes & $16(19)$ & $18(20)$ \\
\hline Unknown & $62(73)$ & $62(68)$ \\
\hline \multicolumn{3}{|c|}{ Karnofsky performance score } \\
\hline$\leq 70$ & $25(29)$ & $29(32)$ \\
\hline$\geq 80$ & $60(71)$ & $62(68)$ \\
\hline \multicolumn{3}{|c|}{ Number of pre-treatment symptoms } \\
\hline 1 & $25(29)$ & $29(32)$ \\
\hline$\geq 2$ & $49(58)$ & $51(56)$ \\
\hline Unknown & $11(13)$ & $11(12)$ \\
\hline \multicolumn{3}{|l|}{ Gender } \\
\hline Female & $36(42)$ & $38(42)$ \\
\hline Male & $49(58)$ & $53(58)$ \\
\hline \multicolumn{3}{|l|}{ Age at radiotherapy } \\
\hline$\leq 60$ Years & $41(48)$ & $44(48)$ \\
\hline$\geq 61$ Years & $44(52)$ & $47(52)$ \\
\hline \multicolumn{3}{|c|}{ Neurosurgical resection } \\
\hline No & $16(19)$ & $18(20)$ \\
\hline Yes & $69(81)$ & $73(80)$ \\
\hline \multicolumn{3}{|l|}{ Extent of resection } \\
\hline GTR & $18(26)$ & $21(29)$ \\
\hline STR & $44(64)$ & $45(62)$ \\
\hline Not specified & $7(10)$ & $7(10)$ \\
\hline
\end{tabular}

GBM: Glioblastoma multiforme, MIB1: molecular immunology Borstel 1, MGMT: $O^{6}$-methylguanine-DNA methyl-transferase, GTR: gross total resection, STR: subtotal resection.

$(\mathrm{HR}=3.63,95 \% \mathrm{CI}=1.39-9.80, p=0.009), \mathrm{KPS} \geq 80(\mathrm{HR}=2.01$, $95 \% \mathrm{CI}=1.13-3.50, p=0.018)$ and upfront resection $(\mathrm{HR}=3.29$, $95 \% \mathrm{CI}=1.75-5.95, p<0.001)$ maintained significance. 
Table II. Local control rates at 1 and 2 years after the start of radiotherapy $(n=85)$.

\begin{tabular}{|c|c|c|c|}
\hline Factor & $\begin{array}{c}1 \text { Year } \\
(\%)\end{array}$ & $\begin{array}{c}2 \text { Years } \\
(\%)\end{array}$ & $p$-Value \\
\hline \multicolumn{4}{|c|}{ Number of GBM lesions } \\
\hline Single & 90 & 71 & \multirow[t]{2}{*}{0.573} \\
\hline Multiple & 100 & 60 & \\
\hline \multicolumn{4}{|l|}{ Main site of GBM } \\
\hline Thalamus & 100 & 100 & \multirow[t]{10}{*}{0.761} \\
\hline Temporal & 85 & 69 & \\
\hline Frontal & 83 & 73 & \\
\hline Parietal & 100 & 100 & \\
\hline Occipital & 100 & 100 & \\
\hline Parieto-occipital & 100 & 40 & \\
\hline Fronto-parietal & 100 & 100 & \\
\hline Temporo-frontal & 100 & 67 & \\
\hline Temporo-parietal & 100 & 57 & \\
\hline Other sites & 80 & 80 & \\
\hline \multicolumn{4}{|c|}{ Maximum cumulative diameter } \\
\hline$<40 \mathrm{~mm}$ & 90 & 61 & \multirow[t]{2}{*}{0.738} \\
\hline$\geq 40 \mathrm{~mm}$ & 92 & 78 & \\
\hline \multicolumn{4}{|c|}{ Ki-67/MIB 1 labeling index } \\
\hline$<25 \%$ & 89 & 72 & \multirow[t]{2}{*}{0.752} \\
\hline$\geq 25 \%$ & 95 & 81 & \\
\hline \multicolumn{4}{|c|}{ MGMT promoter methylation } \\
\hline No & 80 & 40 & \multirow[t]{2}{*}{0.103} \\
\hline Yes & 92 & 67 & \\
\hline \multicolumn{4}{|c|}{ Karnofsky performance score } \\
\hline$\leq 70$ & 86 & 77 & \multirow[t]{2}{*}{0.656} \\
\hline$\geq 80$ & 92 & 67 & \\
\hline \multicolumn{4}{|c|}{ Number of pre-treatment symptoms } \\
\hline 1 & 89 & 83 & \multirow[t]{2}{*}{0.166} \\
\hline$\geq 2$ & 95 & 64 & \\
\hline \multicolumn{4}{|l|}{ Gender } \\
\hline Female & 92 & 73 & \multirow[t]{2}{*}{0.230} \\
\hline Male & 90 & 68 & \\
\hline \multicolumn{4}{|l|}{ Age at radiotherapy } \\
\hline$\leq 60$ Years & 88 & 75 & \multirow[t]{2}{*}{0.886} \\
\hline$\geq 61$ Years & 93 & 63 & \\
\hline \multicolumn{4}{|c|}{ Neurosurgical resection } \\
\hline No & 100 & 100 & \multirow[t]{2}{*}{0.764} \\
\hline Yes & 90 & 67 & \\
\hline \multicolumn{4}{|l|}{ Extent of resection } \\
\hline GTR & 94 & 74 & \multirow[t]{2}{*}{0.029} \\
\hline STR & 89 & 64 & \\
\hline
\end{tabular}

GBM: Glioblastoma multiforme, MIB: molecular immunology Borstel 1, MGMT: $O^{6}$-methylguanine-DNA methyl-transferase, GTR: gross total resection, STR: subtotal resection. Bold $p$-values were significant.
Table III. Survival rates at 1 and 2 years after the start of radiotherapy $(n=91)$.

\begin{tabular}{|c|c|c|c|}
\hline Factor & $\begin{array}{c}1 \text { Year } \\
(\%)\end{array}$ & $\begin{array}{c}2 \text { Years } \\
(\%)\end{array}$ & $p$-Value \\
\hline \multicolumn{4}{|c|}{ Number of GBM lesions } \\
\hline Single & 70 & 57 & \multirow[t]{2}{*}{0.056} \\
\hline Multiple & 33 & 33 & \\
\hline \multicolumn{4}{|l|}{ Main site of GBM } \\
\hline Thalamus & 20 & 20 & \multirow[t]{10}{*}{0.061} \\
\hline Temporal & 76 & 64 & \\
\hline Frontal & 58 & 47 & \\
\hline Parietal & 30 & 20 & \\
\hline Occipital & 50 & 50 & \\
\hline Parieto-occipital & 71 & 71 & \\
\hline Fronto-parietal & 75 & 25 & \\
\hline Temporo-frontal & 100 & 100 & \\
\hline Temporo-parietal & 78 & 67 & \\
\hline Other sites & 80 & 60 & \\
\hline \multicolumn{4}{|c|}{ Maximum cumulative diameter } \\
\hline$<40 \mathrm{~mm}$ & 66 & 50 & \multirow[t]{2}{*}{0.953} \\
\hline$\geq 40 \mathrm{~mm}$ & 52 & 45 & \\
\hline \multicolumn{4}{|c|}{ Ki-67/MIB 1 labeling index } \\
\hline$<25 \%$ & 65 & 54 & \multirow[t]{2}{*}{0.149} \\
\hline$\geq 25 \%$ & 52 & 42 & \\
\hline \multicolumn{4}{|c|}{ MGMT promoter methylation } \\
\hline No & 18 & 9 & \multirow[t]{2}{*}{0.004} \\
\hline Yes & 72 & 61 & \\
\hline \multicolumn{4}{|c|}{ Karnofsky performance score } \\
\hline$\leq 70$ & 45 & 34 & \multirow[t]{2}{*}{0.022} \\
\hline$\geq 80$ & 73 & 61 & \\
\hline \multicolumn{4}{|c|}{ Number of pre-treatment symptoms } \\
\hline 1 & 55 & 48 & \multirow[t]{2}{*}{0.615} \\
\hline$\geq 2$ & 67 & 51 & \\
\hline \multicolumn{4}{|l|}{ Gender } \\
\hline Female & 58 & 47 & \multirow[t]{2}{*}{0.490} \\
\hline Male & 68 & 57 & \\
\hline \multicolumn{4}{|l|}{ Age at radiotherapy } \\
\hline$\leq 60$ Years & 70 & 61 & \multirow[t]{2}{*}{0.162} \\
\hline$\geq 61$ Years & 57 & 45 & \\
\hline \multicolumn{4}{|c|}{ Neurosurgical resection } \\
\hline No & 28 & 22 & \multirow[t]{2}{*}{$<0.001$} \\
\hline Yes & 73 & 60 & \\
\hline \multicolumn{4}{|l|}{ Extent of resection } \\
\hline GTR & 81 & 71 & \multirow[t]{2}{*}{0.077} \\
\hline STR & 69 & 56 & \\
\hline
\end{tabular}

GBM: Glioblastoma multiforme, MIB: molecular immunology Borstel 1, MGMT: $O^{6}$-methylguanine-DNA methyl-transferase, GTR: gross total resection, STR: subtotal resection. Bold $p$-values were significant.

\section{Discussion}

The treatment generally considered standard for GBM includes maximum neurosurgical resection followed by concurrent radiochemotherapy (60 Gy in 30 fractions plus temozolomide) and six courses of temozolomide alone (5-7). In a randomized trial, this regimen led to a median survival time of 14.6 months and 2-year, 3-year and 5-year survival rates of $27.2 \%, 16.0 \%$ and $9.8 \%$, respectively $(5,6)$. When looking at these low survival rates, it becomes obvious that the outcomes of patients with GBM require further improvement. Many pre-clinical and clinical studies were performed to contribute to better understanding and improved treatment of this malignant disease (11-14). 
From the radiation oncologist's perspective, an important question is related to the optimal dose-fractionation schedule. Already in 1979 , a pooled analysis was presented including data of patients with malignant gliomas treated with surgery plus irradiation in several studies of the Brain Tumor Study Group (15). This analysis demonstrated a dose-effect relationship. Patients receiving 60 Gy had a significantly longer median survival (42 weeks) than patients receiving 55 Gy (36 weeks), 50 Gy (28 weeks) and $\leq 45$ Gy (13.5 weeks). Moreover, a randomized trial demonstrated that $60 \mathrm{~Gy}$ in 30 fractions over 6 weeks was significantly superior to $45 \mathrm{~Gy}$ in 20 fractions over 4 weeks ( $p=0.007)$ (16). In 2001, a phase III trial compared four treatment regimens for newly diagnosed GBM (17). Treatment regimens included acceleratedhyperfractionated radiotherapy (70.4 Gy, 2×1.6 Gy/day) with or without a radiosensitizer (difluromethylornithine=DFMO) and normofractionated radiotherapy $(59.4 \mathrm{~Gy}, 1 \times 1.8 \mathrm{~Gy} /$ day $)$ with or without DFMO. The four groups were balanced for age, KPS and extent of resection. Both acceleratedhyperfractionated radiotherapy and addition of DFMO did not lead to improved overall survival and progression-free survival (17). Thus, total doses of 59.4 Gy and 60.0 Gy are considered optimal for the treatment of GBM.

However, it has been recognized that elderly patients and patients with a poor performance status have less favorable survival prognoses $(4,18)$. Moreover, these patients may not be able to withstand an intensive tri-modality treatment (5, $6)$. In 2004, a randomized trial of 100 patients with GBM aged $\geq 60$ years compared shorter-course radiotherapy (40 Gy in 15 fractions over 3 weeks) to longer-course radiotherapy (60 Gy in 30 fractions over 6 weeks for survival (9). Median survival and survival rates at 6 months were similar $(p=0.57)$, and shorter-course radiotherapy was considered a reasonable option for GBM patients $\geq 60$ years of age.

Shorter-course radiotherapy may also be reasonable for patients with limited survival prognoses to avoid that they have to spend more than necessary of their remaining lifespan receiving treatment for GBM. It would be important to be able to judge a patient's survival prognosis prior to assigning a treatment regimen. Prognostic factors of survival can guide the physicians during this process. Moreover, prognostic factors of local control of the GBM are important for selecting the optimal individual treatment, particularly because GBM does not metastasize outside the brain.

In the present study, the data of 91 patients irradiated for GBM were analyzed to identify predictors of both local control and survival. The aim to facilitate the estimation of the survival of patients with GBM has been previously pursued (18). In 2004, a recursive partitioning analysis was presented, which was based on the three prognostic factors age, KPS and extent of resection. The groups with the highest risk of death included all patients $>65$ years of age and patients $40-65$ years of age with either KPS $<80$ or biopsy only (18). In contrast to our present study, local control of GBM was not investigated. Moreover, since 2004 the treatment of GBM has changed considerably, particularly after publication of the randomized trial of Stupp et al. in 2005 (5).

In this study, improved local control of GBM was significantly associated with GTR. Thus, GTR should be aimed at whenever reasonably possible considering potential damage to important brain structures as well as the patient's performance score and comorbidity index. Worse survival was significantly associated in both univariate and multivariate analyses with absence of MGMT promoter methylation, worse KPS ( $\leq 70)$ and no upfront resection. In addition, multifocal GBM showed a trend for worse survival on univariate analysis. Considering the randomized trial of Roa et al., patients with one or more of these negative prognostic factors may be considered for shorter-course with 40 Gy in 15 fractions over 3 weeks instead of longer-course radiotherapy over 6 weeks (9). According to the randomized trial of Perry et al., the addition of temozolomide to shortercourse radiotherapy resulted in improved survival in elderly patients ( $\geq 65$ years) and may be considered for also for patients with negative prognostic factors identified in this study who likely will tolerate the combined treatment (10). Selected patients may even be candidates for temozolomide alone $(19,20)$. In contrast, a retrospective study of 112 patients aged $\geq 60$ years did not find a significant benefit for the addition of temozolomide to shorter-course radiotherapy (21). Particularly patients without MGMT promoter methylation may not significantly benefit from temozolomide (5-7, 19, 20).

MGMT promoter methylation $(5-7,10,19,20)$, a better performance score $(4,18,22,23)$, a greater extent of resection $(4,18,22,23)$ and unifocal GBM (24-26) were previously reported as predictors of improved survival of patients with GBM, consistent with the results of the present study. Therefore, these results will likely contribute to the personalization of the treatment of patients with GBM. However, when interpreting the results of this study, one should be aware of its limitations including the retrospective design, which might have led to hidden selection biases. Although patients alive at the last contact must have had a follow up of at least 24 months, some deaths might have been missed due to the retrospective nature of the data. Moreover, the patients were treated during a comparably long time period of 15 years during which treatment concepts for recurrence of GBM have changed. This likely had an impact on the patients' survival.

In summary, in patients receiving longer-course radiotherapy for GBM, better local control was associated with GTR and better survival with MGMT promoter methylation, KPS $\geq 80$, upfront resection and unifocal GBM. These predictors of treatment outcomes may guide physicians when designing personalized treatment programs for patients with GBM. 


\section{Conflicts of Interest}

The Authors report no conflicts of interest related to the present study.

\section{Authors' Contributions}

The study was designed by all Authors. J.W. collected the data that were analyzed by all Authors. The draft of the article was written and finally approved by J.W., S.E.S. and D.R.

\section{References}

1 Ostrom QT, Gittleman H, Fulop J, Liu M, Blanda R, Kromer C, Wolinsky Y, Kruchko C and Barnholtz-Sloan JS: CBTRUS statistical report: Primary brain and central nervous system tumors diagnosed in the United States in 2008-2012. Neuro Oncol 17(suppl 4): iv1-iv62, 2015. PMID: 26511214. DOI: 10.1093/neuonc/nov189

2 Alexander BM and Cloughesy TF: Adult glioblastoma. J Clin Oncol 35: 2402-2409, 2017. PMID: 28640706. DOI: 10.1200/ JCO.2017.73.0119

3 Gittleman H, Boscia A, Ostrom QT, Truitt G, Fritz Y, Kruchko $\mathrm{C}$ and Barnholtz-Sloan JS: Survivorship in adults with malignant brain and other central nervous system tumor from 2000-2014. Neuro Oncol 20(suppl 7): vii6-vii16, 2018. PMID: 29850889. DOI:10.1093/neuonc/noy090

4 Delgado-Lopez PD and Corrales-Garcia EM: Survival in glioblastoma: A review on the impact of treatment modalities. Clin Transl Oncol 18: 1062-1071, 2016. PMID: 26960561. DOI: 10.1007/s12094-016-1497-x

5 Stupp R, Mason WP, van den Bent MJ, Weller M, Fisher B, Taphoorn MJ, Belanger K, Brandes AA, Marosi C, Bogdahn U, Curschmann J, Janzer RC, Ludwin SK, Gorlia T, Allgeier A, Lacombe D, Cairncross JG, Eisenhauer E and Mirimanoff RO; European Organisation for Research and Treatment of Cancer Brain Tumor and Radiotherapy Groups; National Cancer Institute of Canada Clinical Trials Group: Radiotherapy plus concomitant and adjuvant temozolomide for glioblastoma. $\mathrm{N}$ Engl J Med 352: 987-996, 2005. PMID: 15758009. DOI: 10.1056/NEJMoa043330

6 Stupp R, Hegi ME, Mason WP, van den Bent MJ, Taphoorn MJ, Janzer RC, Ludwin SK, Allgeier A, Fisher B, Belanger K, Hau P, Brandes AA, Gijtenbeek J, Marosi C, Vecht CJ, Mokhtari K, Wesseling P, Villa S, Eisenhauer E, Gorlia T, Weller M, Lacombe D, Cairncross JG and Mirimanoff RO; European Organisation for Research and Treatment of Cancer Brain Tumour and Radiation Oncology Groups; National Cancer Institute of Canada Clinical Trials Group: Effects of radiotherapy with concomitant and adjuvant temozolomide versus radiotherapy alone on survival in glioblastoma in a randomised phase III study: 5-year analysis of the EORTC-NCIC trial. Lancet Oncol 10: 459-466, 2009. PMID: 19269895. DOI: 10.1016/S1470-2045(09)70025-7

7 Stupp R, Brada M, van den Bent MJ, Tonn JC and Pentheroudakis G; ESMO Guidelines Working Group: Highgrade glioma: ESMO clinical practice guidelines for diagnosis, treatment and follow-up. Ann Oncol 25(suppl 3): iii93-101, 2014. PMID: 24782454. DOI: 10.1093/annonc/mdu050
8 Minniti G and Enrici RM: Radiation therapy for older adults with glioblastoma: Radical treatment, palliative treatment, or no treatment at all? J Neurooncol 120: 225-233, 2014. PMID: 25096799. DOI: $10.1007 / \mathrm{s} 11060-014-1566-3$

9 Roa W, Brasher PM, Bauman G, Anthes M, Bruera E, Chan A, Fisher B, Fulton D, Gulavita S, Hao C, Husain S, Murtha A, Petruk K, Stewart D, Tai P, Urtasun R, Cairncross JG and Forsyth P: Abbreviated course of radiation therapy in older patients with glioblastoma multiforme: a prospective randomized clinical trial. J Clin Oncol 22: 1583-1588, 2004. PMID: 15051755. DOI: $10.1200 / J C O .2004 .06 .082$

10 Perry JR, Laperriere N, O'Callaghan CJ, Brandes AA, Menten J, Phillips C, Fay M, Nishikawa R, Cairncross JG, Roa W, Osoba D, Rossiter JP, Sahgal A, Hirte H, Laigle-Donadey F, Franceschi E, Chinot O, Golfinopoulos V, Fariselli L, Wick A, Feuvret L, Back M, Tills M, Winch C, Baumert BG, Wick W, Ding $\mathrm{K}$ and Mason WP; Trial Investigators: Short-course radiation plus temozolomide in elderly patients with glioblastoma. N Engl J Med 376: 1027-1037, 2017. PMID: 28296618. DOI: 10.1056/NEJMoa1611977

11 Antonopoulos M, van Gool SW, Dionysiou D, Graf N and Stamatakos G: Immune phenotype correlates with survival in patients with GBM treated with standard temozolomide-based therapy and immunotherapy. Anticancer Res 39: 2043-2051, 2019. PMID: 30952748. DOI: 10.21873/anticanres.13315

12 Helson L and Majeed M: Pleiotropic chemotherapy to abrogate glioblastoma multiforme migration/invasion. Anticancer Res 39: 3423-3427, 2019. PMID: 31262865. DOI: 10.21873/anticanres. 13487

$13 \mathrm{Kim}$ GW, Lee DH, Yeon SK, Jeon YH, Yoo J, Lee SW and Kwon SH: Temozolomide-resistant glioblastoma depends on HDAC6 activity through regulation of DNA mismatch repair. Anticancer Res 39: 6731-6741, 2019. PMID: 31810938. DOI: 10.21873/anticanres.13888

14 Han HR, Park SA, Ahn S, Jeun SS and Ryu CH: Evaluation of combination treatment effect with TRAIL-secreting mesenchymal stem cells and compound $\mathrm{C}$ against glioblastoma. Anticancer Res 39: 6635-6643, 2019. PMID: 31810928. DOI: 10.21873/anticanres.13878

15 Walker MD, Strike TA and Sheline GE: An analysis of doseeffect relationship in the radiotherapy of malignant gliomas. Int J Radiat Oncol Biol Phys 5: 1725-1731, 1979. PMID: 231022. DOI: 10.1016/0360-3016(79)90553-4

16 Bleehen NM and Stenning SP: A Medical Research Council trial of two radiotherapy doses in the treatment of grades 3 and 4 astrocytoma. The Medical Research Council Brain Tumour Working Party. Br J Cancer 64: 769-774, 1991. PMID: 1654987. DOI: $10.1038 /$ bjc.1991.396

17 Prados MD, Wara WM, Sneed PK, McDermott M, Chang SM, Rabbitt J, Page M, Malec M, Davis RL, Gutin PH, Lamborn K, Wilson CB, Phillips TL and Larson DA: Phase III trial of accelerated hyperfractionation with or without difluromethylornithine (DFMO) versus standard fractionated radiotherapy with or without DFMO for newly diagnosed patients with glioblastoma multiforme. Int J Radiat Oncol Biol Phys 49: 71-77, 2001. PMID: 11163499. DOI: 10.1016/s0360-3016(00)01458-9

18 Lamborn KR, Chang SM and Prados MD: Prognostic factors for survival of patients with glioblastoma: recursive partitioning analysis. Neuro Oncol 6: 227-235, 2004. PMID: 15279715. DOI: $10.1215 / \mathrm{S} 1152851703000620$ 
19 Malmström A, Grønberg BH, Marosi C, Stupp R, Frappaz D, Schultz H, Abacioglu U, Tavelin B, Lhermitte B, Hegi ME, Rosell J and Henriksson R; Nordic Clinical Brain Tumour Study Group (NCBTSG): Temozolomide versus standard 6-week radiotherapy versus hypofractionated radiotherapy in patients older than 60 years with glioblastoma: The Nordic randomised, phase 3 trial. Lancet Oncol 13: 916-926, 2012. PMID: 22877848. DOI: 10.1016/S1470-2045(12)70265-6

20 Wick W, Platten M, Meisner C, Felsberg J, Tabatabai G, Simon M, Nikkhah G, Papsdorf K, Steinbach JP, Sabel M, Combs SE, Vesper J, Braun C, Meixensberger J, Ketter R, Mayer-Steinacker $\mathrm{R}$, Reifenberger $\mathrm{G}$ and Weller M; NOA-08 Study Group of Neuro-oncology Working Group (NOA) of German Cancer Society: Temozolomide chemotherapy alone versus radiotherapy alone for malignant astrocytoma in the elderly: the NOA-08 randomised, phase 3 trial. Lancet Oncol 13: 707-715, 2012. PMID: 22578793. DOI: 10.1016/S1470-2045(12)70164-X

21 Cao JQ, Fisher BJ, Bauman GS, Megyesi JF, Watling CJ and Macdonald DR: Hypofractionated radiotherapy with or without concurrent temozolomide in elderly patients with glioblastoma multiforme: a review of ten-year single institutional experience. J Neurooncol 107: 395-405, 2012. PMID: 22105851. DOI: 10.1007/s11060-011-0766-3

22 Mohan DS, Suh JH, Phan JL, Kupelian PA, Cohen BH and Barnett GH: Outcome in elderly patients undergoing definitive surgery and radiation therapy for supratentorial glioblastoma multiforme at a tertiary care institution. Int J Radiat Oncol Biol Phys 42: 981-987, 1998. PMID: 9869219. DOI: 10.1016/s03603016(98)00296-x
23 Scott JG, Bauchet L, Fraum TJ, Nayak L, Cooper AR, Chao ST, Suh JH, Vogelbaum MA, Peereboom DM, Zouaoui S, MathieuDaudé H, Fabbro-Peray P, Rigau V, Taillandier L, Abrey LE, DeAngelis LM, Shih JH and Iwamoto FM: Recursive partitioning analysis of prognostic factors for glioblastoma patients aged 70 years or older. Cancer 118: 5595-5600, 2012. PMID: 22517216. DOI: $10.1002 / \mathrm{cncr} .27570$

24 Patil CG, Yi A, Patil CG, Yi A, Elramsisy A, Hu J, Mukherjee D, Irvin DK, Yu JS, Bannykh SI, Black KL and Nuño M: Prognosis of patients with multifocal glioblastoma: a casecontrol study. J Neurosurg 117: 705-711, 2012. PMID: 22920963. DOI: $10.3171 / 2012.7 . J N S 12147$

25 Syed M, Liermann J, Verma V, Bernhardt D, Bougatf N, Paul A, Rieken S, Debus J and Adeberg S: Survival and recurrence patterns of multifocal glioblastoma after radiation therapy. Cancer Manag Res 10: 4229-4235, 2018. PMID: 30323678. DOI: $10.2147 / C M A R . S 165956$

26 Haque W, Verma V, Brian Butler E and Teh BS: Patterns of management and outcomes of unifocal versus multifocal glioblastoma. J Clin Neurosci 76: 154-160, 2020. PMID: 32291240. DOI: 10.1016/j.jocn.2020.04.002
Received October 19, 2020

Revised October 29, 2020

Accepted October 30, 2020 